\title{
DETERMINAN FAKTOR YANG BERPENGARUH PADA PEMBERIAN ASI EKSKLUSIF DI INDONESIA
}

\section{Determinant Factors That Influence to Exclusive Breastfeeding}

\author{
Rizqi Fadlliyyah \\ Departemen Promosi Kesehatan dan Ilmu Perilaku, Fakultas Kesehatan Masyarakat, \\ Universitas Airlangga \\ email: ulfi.rizqi.fadlliyyah-2015@fkm.unair.ac.id
}

\begin{abstract}
Exclusive breastfeeding is one of the efforts to reduce the prevalence of infant mortality in Indonesia. If more babies get exclusive breastfeeding, it can improve the quality of baby's health. Breast milk also helps to build the baby's immune system, and giving exclusive breastfeeding during pregnancy to babies can help reduce fat. Indonesia is one of the countries that provides exclusive breast milk, hasn't reached the WHO target. Exclusive breastfeeding in Indonesia is related to several things, such as maternal factors, career woman, cultural factors, and impact formula milk campaign. Giving breast milk which is not done exclusively can increase the risk of stunting, because it easily involves infections and diarrhea. From birth to six months, every baby should get exclusive breastfeeding. However, the implementation of exclusive breastfeeding was not as expected. There are several factors in the practice of exclusive breastfeeding. This article discusses several factors which can affect exclusive breastfeeding. Obtained from the analysis of several review articles or literature, there are 16 factors that can affect exclusive breastfeeding, such as; maternal parity, work cycle, mother's knowledge, mother's attitude, mother's actions, family or husband support, education level, early breastfeeding initiative, maternal age, health worker support, availability of space lactation in the workplace, information exposure, family income, community environment, formula milk, and the psychological condition of the mother it self.
\end{abstract}

Keywords: breast milk, determinant factors, exclusive breastfeeding

\begin{abstract}
Abstrak
Pemberian ASI secara eksklusif merupakan salah satu upaya untuk menurunkan prevalensi kematian bayi di Indonesia. Semakin banyak jumlah bayi yang mendapatkan ASI eksklusif, dapat meningkatkan kualitas kesehatan bayi. ASI berperan dalam pembentukan sistem kekebalan tubuh bayi, dan memberikan ASI eksklusif pada bayi dapat membantu mengurangi lemak pada ibu sewaktu hamil. Negara Indonesia merupakan salah satu negara yang cakupan pemberian air susu ibu eksklusif belum mencapai target yang ditetapkan WHO. Rendahnya cakupan pemberian ASI eksklusif di Indonesia dikarenakan beberapa hal yaitu seperti faktor psikologis ibu, ibu bekerja, faktor budaya, hingga karena promosi susu formula. Pemberian ASI yang tidak dilakukan secara eksklusif dapat meningkatkan risiko anak mengalami stunting karena lebih mudah terkena infeksi dan diare. Setiap bayi berhak untuk mendapatkan ASI eksklusif sejak dilahirkan hingga berusia enam bulan. Namun dalam pelaksanaan pemberian ASI eksklusif tidak berjalan dengan lancar seperti yang diharapkan. Terdapat beberapa faktor yang dapat mempengaruhi praktik pemberian ASI eksklusif. Oleh karena itu artikel ini membahas tentang apa saja faktor-faktor yang dapat mempengaruhi pemberian ASI eksklusif di negara Indonesia. Berdasarkan kajian analisis beberapa artikel atau literature review, setidaknya didapatkan 16 determinan faktor yang dapat mempengaruhi pemberian ASI eksklusif diantaranya antara lain paritas ibu (jumlah kelahiran hidup yang dimiliki seorang ibu), pekerjaan ibu, pengetahuan ibu, sikap ibu, tindakan ibu, dukungan keluarga atau suami, tingkat pendidikan, IMD (Inisiasi Menyusui Dini), usia ibu, dukungan petugas kesehatan, ketersediaan ruang laktasi di tempat kerja, keterpaparan informasi, pendapatan keluarga, lingkungan, susu formula, dan kondisi psikologis ibu.

Kata kunci: ASI, Faktor Pengaruh, ASI Eksklusif
\end{abstract}




\section{PENDAHULUAN}

Angka kematian bayi di Indonesia masih sangat tinggi yang sekaligus menjadi masalah kesehatan anak yang terus berupaya untuk mengurangi prevalensi kejadian tersebut. Kematian bayi disebabkan oleh beberapa hal yakni antara lain seperti kelahiran bayi yang prematur, infeksi saat kelahiran, kelainan bawaan (gen), tidak melakukan IMD (Inisiasi Menyusui Dini) memicu pemberian Air Susu Ibu (ASI) eksklusif yang rendah atau bahkan tidak eksklusif selama enam bulan (BKKBN, 2012).

ASI merupakan salah satu kebutuhan bayi yang harus dipenuhi oleh ibu selama bayi baru lahir hingga setidaknya bayi berusia enam bulan (Nasution et al., 2016). ASI memiliki peranan penting dalam pembentukan daya tahan tubuh bayi. Pemberian ASI yang dilakukan secara eksklusif setara dengan menyelamatkan 804.000 anak dari kematian di tahun 2011 (WHO, 2014). ASI memiliki banyak manfaat tidak hanya bagi bayi tapi juga bermanfaat bagi ibu. Selain dapat meningkatkan sistem kekebalan tubuh bagi bayi, memberikan ASI eksklusif pada bayi dapat membantu mengurangi lemak pada ibu sewaktu hamil (Prasetyono, 2009).

ASI eksklusif yang dimaksud adalah pemberian ASI mulai dari bayi baru lahir hingga berusia enam bulan tanpa memberikan minuman atau makanan lain selain ASI kecuali obat atau vitamin. Setelah enam bulan, Makanan Pendamping ASI (MP-ASI) baru bisa diberikan pada bayi dan ASI tetap dapat dilanjutkan hingga usia bayi 24 bulan. Jika pemberian MP-ASI diberikan sebelum enam bulan, maka dapat mengganggu sistem pencernaan bayi (Prasetyono, 2009).

Cakupan pemberian ASI eksklusif pada bayi usia 0 hingga 6 bulan secara global hanya sebesar 38\% bayi yang mendapatkan ASI eksklusif dari target capaian yang ditetapkan WHO sebesar 50\% (WHO, 2014). Cakupan ASI eksklusif di negara Indonesia yakni sebesar $35,73 \%$ dan belum memenuhi target WHO (Prasetyono, 2009).

Cakupan ASI eksklusif yang rendah di masyarakat dapat dipengaruhi oleh beberapa hal seperti yang terdapat dalam Profil Kesehatan Provinsi Jawa Timur tahun 2016 antara lain disebabkan oleh faktor psikologis ibu, faktor pemberi pelayanan persalinan, faktor ibu bekerja, faktor budaya, hingga faktor promosi susu formula (Dinkes Jatim, 2016).
Pemberian ASI yang tidak eksklusif kerap dikaitkan dengan masalah kesehatan yang dapat terjadi pada anak. Salah satunya dampak dari pemberian ASI yang tidak eksklusif juga turut meningkatkan risiko anak mengalami stunting atau kondisi tinggi badan seorang anak yang jauh lebih pendek dibandingkan tinggi badan anak lain seusianya. Pemberian ASI yang kurang dari enam bulan dapat meningkatkan risiko stunting karena bayi lebih mudah terkena infeksi atau diare (Anugerahani dan Kartasurya, 2012).

Meskipun manfaat yang dimiliki ASI sangat banyak, tetapi ditemukan masih banyak bayi yang belum mendapatkan ASI eksklusif secara maksimal. Diperlukan dukungan dari berbagai pihak baik dari keluarga, masyarakat, serta tenaga kesehatan agar turut mensukseskan pemberian ASI eksklusif dengan gencar menggalakkan ASI eksklusif.

Pemberian ASI eksklusif pun telah diwajibkan oleh pemerintah selama enam bulan yang tertera dalam pasal 128 Undang-Undang nomor 36 tahun 2009 tentang Kesehatan. Di dalamnya menyebutkan bahwa setiap bayi berhak mendapatkan air susu ibu eksklusif sejak dilahirkan selama 6 (enam) bulan, kecuali atas indikasi medis.

Berdasarkan Target Gizi Global 2025, WHO menetapkan target cakupan pemberian ASI eksklusif dalam enam bulan pertama setidaknya mencapai $50 \%$. Namun faktanya, secara global hanya $38 \%$ bayi usia 0 hingga 6 bulan yang mendapat ASI eksklusif. Analisis terbaru menunjukkan bahwa pemberian ASI non-eksklusif berkontribusi pada $11,6 \%$ kematian pada anak di bawah usia 5 tahun (WHO, 2014). Cakupan keseluruhan pemberian ASI eksklusif pada bayi hingga usia enam bulan di negara Indonesia adalah sebesar 35,73\% dan belum memenuhi target WHO (Prasetyono, 2009).

Berdasarkan uraian yang telah dijelaskan sebelumnya, maka akan dibahas lebih mendalam mengenai faktor-faktor apa saja yang dapat berpengaruh dalam pemberian ASI eksklusif.

\section{HASIL DAN PEMBAHASAN}

Berdasarkan kajian atau analisis secara literature review dari beberapa artikel penelitian diperoleh hasil beberapa faktor yang dapat mempengaruhi pemberian ASI eksklusif, yakni sebagai berikut : 


\section{Paritas Ibu}

Paritas atau yang dimaksud dengan jumlah kelahiran hidup yang dimiliki oleh seorang ibu (BKKBN, 2006). Hasil penelitian terdahulu menyebutkan bahwa paritas memiliki hubungan dengan pemberian ASI eksklusif (Devita, 2013). Hal ini dikarenakan bahwa ibu yang memiliki jumlah anak yang rendah atau kurang dari tiga orang akan memiliki lebih banyak waktu untuk memberikan ASI pada bayi setiap waktu, dibandingkan ibu yang memiliki tingkat paritas tinggi. Ibu yang memiliki paritas rendah cenderung akan menyusui anaknya secara eksklusif karena waktu bersama anaknya lebih banyak.

2. Pekerjaan Ibu

Ibu yang bekerja di luar rumah dan harus meninggalkan anak lebih dari 7 jam berpotensi terhalang waktu yang dimiliki untuk menyusui karena jadwal bekerja mereka, dibandingkan ibu rumah tangga yang dapat menyusui anaknya secara tidak perlu terjadwal (Dinkes, Jatim, 2016).

Selain itu alasan mengapa ibu bekerja tidak bisa memberikan ASI eksklusif karena selain faktor bekerja juga dikarenakan tidak ada fasilitas seperti ruangan khusus untuk memerah ASI sehinggga praktik pemberian ASI eksklusif tidak tercapai (Sugiarti et al., 2011). Selain itu, ibu bekerja juga sibuk dan sulit untuk meninggalkan pekerjaan. Penelitian lain juga menunjukkan bahwa ibu bekerja berpengaruh dalam pemberian ASI eksklusif (Rahmawati, 2010).

Masa cuti hamil dan menyusui yang ditetapkan oleh pemerintah juga hanya 3 bulan, sedangkan anjuran pemberian ASI eksklusif adalah enam bulan. Ibu yang bekerja memiliki kesempatan terbatas untuk memberikan ASI eksklusif (Eugenie et al., 2015). Umumnya, ibu bekerja cenderung memberikan pengganti ASI ketika mulai aktif bekerja. Ibu yang memiliki pengetahuan yang benar tentang menyusui serta lingkungan kerja yang mendukung, ibu bekerja akan tetap dapat memberikan ASI secara eksklusif. Sedangkan ibu yang tidak bekerja lebih banyak memiliki waktu untuk menyusui anaknya.

\section{Pengetahuan Ibu}

Ibu yang memiliki pengetahuan kurang terutama tentang manfaat ASI cenderung tidak memberikan ASI eksklusif pada anaknya (Devita, 2013). Namun berbeda dengan penelitian sebelumnya yang menyebutkan bahwa tidak ada pengaruh bagi pengetahuan dengan pemberian ASI eksklusif (Rahmawati, 2010). Hal ini ditandai dengan sebagian besar ibu yang memiliki pengetahuan tentang ASI yang baik tapi tidak memberikan ASI eksklusif pada anaknya. Pendapat Azwar bahwa seseorang yang memiliki pengetahuan yang baik belum tentu akan berperilaku baik atau positif pula, jika kesadaran dalam berperilaku tersebut tidak ada. Selain itu pengetahuan responden yang baik maka akan memberikan ASI eksklusif meskipun ASInya lancar atau cukup, sehingga ibu tidak memberikan makanan tambahan selain air susu ibu (Eugenie et al., 2015). Pengetahuan juga dapat dipengaruhi oleh lingkungan. Penelitian lain juga menunjukkan bahwa ibu yang memiliki pengetahuan tinggi akan diwujudkan ke dalam sebuah tindakan (Aprilia, 2012). Tindakan pemberian ASI eksklusif dapat terwujud jika ibu memahami dan mau melakukan.

4. Sikap Ibu

Sikap ibu yang positif atau setuju dalam memberikan ASI eksklusif belum tentu secara nyata memberikan ASI secara eksklusif (Devita, 2013). Hal ini dikarenakan sikap merupakan pandangan atau perasaan yang memicu kecenderungan bertindak tetapi belum terlaksana dalam tindakan nyata. Penelitian lain menunjukkan sikap ibu berhubungan dengan pemberian ASI eksklusif (Abdullah dan Ayubi, 2013). Semakin positif sikap ibu, semakin besar peluang ibu dapat memberikan ASI eksklusif dan begitu juga sebaliknya.

Tindakan ibu

Tindakan seharusnya sudah menunjukkan bahwa orang yang melakukan kegiatan tertentu maka dapat dilihat kesungguhannya terkait suatu hal atau objek. Tetapi pada penelitian sebelumnya menunjukkan ibu yang memiliki tindakan setuju atau positif terkait pemberian ASI secara eksklusif juga ada yang tidak menyusui secara eksklusif (Devita, 2013). Hal ini dikarenakan faktor lain yakni ASI tidak keluar, bayi tidak mau menyusu pada ibu sehingga tidak dapat memberikan ASI secara eksklusif.

5. Dukungan Keluarga atau Suami

Tidak ada hubungan antara dukungan suami atau keluarga dengan pemberian ASI eksklusif (Devita, 2013). Sejalan dengan penelitian sebelumnya menunjukkan bahwa tidak ada pengaruh signifikan antara dukungan suami dengan pemberian ASI eksklusif (Rahmawati, 2010). Namun peran keluarga terutama suami, sangat diperlukan dalam 
memberikan dukungan bagi ibu yang menyusui.

Penelitian lain menjelaskan bahwa dukungan suami sangat berarti bagi istri atau ibu yang sedang memberikan ASI eksklusif (Abdullah dan Ayubi, 2013). Ibu yang mendapat dukungan dari suami cenderung memberikan ASI secara eksklusif daripada ibu yang tidak mendapatkan dukungan dari suami. Pada penelitian lain menunjukkan bahwa pada ibu yang sudah memiliki anak sebelumnya dapat membuat suami memberikan masukan yang baik pada istri terkait menyusui bayi (Masykur dan Nurafifah, 2014).

6. Tingkat Pendidikan

Sebuah studi menyebutkan bahwa tidak ada hubungan antara pendidikan ibu dengan pemberian ASI eksklusif (Sugiarti, et al., 2011). Selain itu juga didapat hasil bahwa ibu yang memiliki pendidikan lanjut cenderung tidak memberikan ASI eksklusif. Sejalan dengan penelitian sebelumnya yang juga menyatakan tidak ada pengaruh signifikan terkait tingkat pendidikan ibu dengan pemberian ASI eksklusif (Rahmawati, 2010).

Namun pada penelitian lain menyebutkan bahwa semakin tinggi pendidikan ibu maka akan semakin baik pula perilaku seseorang dalam pemberian ASI eksklusif (Aprilia, 2012). Karena seharusnya seseorang yang berpendidikan tinggi dapat berpikir dengan bijak apa yang harus dilakukan terkait ASI eksklusif.

7. IMD (Inisiasi Menyusui Dini)

Inisiasi Menyusui Dini (IMD) juga turut berperan dalam keberlanjutan pemberian ASI secara eksklusif pada bayi. Menurut sebuah studi menyebutkan bahwa ibu yang melakukan IMD cenderung memberikan ASI eksklusif pada anaknya, sedangkan ibu yang dulu tidak melakukan IMD cenderung tidak memberikan ASI secara eksklusif (Sugiarti et al., 2011).

8. Usia Ibu

Terdapat pengaruh yang signifikan antara usia ibu dengan pemberian ASI eksklusif (Rahmawati, 2010). Usia menggambarkan kesiapan seseorang secara fisik, mental, dan sosial. Usia ibu juga menentukan kesehatan maternal yang memiliki keterkaitan dengan kondisi kehamilan, persalinan, hingga nifas dan mengasuh anak. Ibu yang berusia kurang dari 20 tahun masih belum matang secara emosional dalam mengurus bayinya. Namun pada ibu yang berusia lebih dari 35 tahun lebih berpengalaman dan siap secara mental dalam mengurus anak. Tetapi, produksi hormone berkurang dan berpotensi mengganggu proses laktasi (menyusui) (Maulida et al., 2015).

9. Dukungan petugas kesehatan

Ada pengaruh signifikan antara dukungan petugas kesehatan dengan pemberian ASI eksklusif (Rahmawati, 2010). Petugas kesehatan memiliki peran penting dalam mempromosikan dan menggalakkan ASI eksklusif. Petugas kesehatan ibarat pemegang peranan kunci dalam penyampaian ASI eksklusif, khususnya petugas kesehatan yang berada di rumah sakit ataupun puskesmas.

Sedangkan di penelitian lain tidak ditemukan hubungan antara dukungan petugas kesehatan dengan pemberian ASI eksklusif (Eugenie et al., 2015). Hal ini ditandai dengan masih terdapat responden yang mendapat bekal susu formula setelah pulang dari melahirkan di fasilitas kesehatan. Peran petugas kesehatan bukan hanya untuk mempromosikan ASI eksklusif pada ibu saat hamil dan setelah melahirkan, tapi turut mencegah maraknya promosi susu formula.

Saat melakukan pelayanan kesehatan, petugas kesehatan dituntut melakukan komunikasi persuasif agar dapat meyakinkan ibu bahwa memberikan ASI eksklusif pada anak harus dan sangat bermanfaat untuk dilakukan (Widdefrita dan Mohanis, 2013). Tetapi masyarakat juga masih ada yang merasa petugas kesehatan belum sepenuhnya melakukan hal tersebut. Peran tenaga atau petugas kesehatan sebenarnya berupaya untuk meningkatkan kesehatan dengan mempengaruhi perilaku melalui komunikasi persuasif, sehingga ibu dapat berperilaku positif dengan memberikan ASI secara eksklusif pada anak.

10. Ketersediaan Ruang Laktasi di Tempat Kerja

Ketersediaan fasilitas untuk ibu menyusui di tempat kerja tidak memiliki hubungan dengan pemberian ASI eksklusif (Abdullah dan Ayubi, 2013). Hal ini ditandai dengan kantor yang menyediakan pojok ASI tetapi ibu bekerja memilih untuk memerah ASI di rumah. Jika sudah berada di tempat kerja, ibu memilih untuk pumping (memerah ASI) di klinik kantor, ruang kerja, hingga di musholla. Tetapi fungsi pojok ASI atau ruang laktasi tetap penting untuk penitipan anak bagi ibu yang sedang bekerja.

11. Keterpaparan Informasi

Sebuah studi menunjukkan bahwa keterpaparan informasi juga berpengaruh dalam pemberian ASI eksklusif (Abdullah dan Ayubi, 
2013). Semakin ibu terpapar informasi, semakin baik pengetahuan ibu terkait ASI eksklusif. Bagi ibu bekerja, keterpaparan informasi tentang ASI eksklusif lebih sering didapat melalui majalah dibandingkan media massa lainnya.

\section{Pendapatan Keluarga}

Tidak ada hubungan antara pendapatan keluarga dengan pemberian ASI eksklusif (Eugenie et al., 2015). Tetapi berbeda dengan penelitian sebelumnya yang menyebutkan bahwa pendapatan keluarga mempengaruhi pola pemberian ASI khususnya di daerah pedesaan (Afifah, 2007). Keluarga dengan tingkat ekonomi tinggi maka rasa gengsi juga cenderung tinggi serta beranggapan bahwa mereka mampu membeli susu formula, sehingga kegiatan menyusui secara eksklusif menjadi terganggu bahkan berkurang.

Jika pada kondisi ekonomi yang rendah, ibu dengan pendidikan menengah sampai dengan tinggi cenderung mencari nafkah untuk menopang kebutuhan ekonomi keluarganya. Namun jika berada di posisi jumlah pemasukan keluarga yang semakin meningkat, menyebabkan daya beli ibu juga meningkat sehingga ibu lebih memilih untuk memberikan susu formula sebagai pengganti ASI agar lebih praktis dan meningkatkan derajat sosial keluarga di mata masyarakat (Hastuti et al., 2015). Karena kondisi ekonomi yang krisis sehingga memaksa ibu untuk bekerja guna mencukupi kebutuhan hidup yang dapat berdampak pada ibu tidak mempunyai kesempatan untuk menyusui anak secara eksklusif (Masykur dan Nurafifah, 2014).

13. Lingkungan

Perilaku ibu dalam pemberian ASI eksklusif juga dipengaruhi oleh lingkungan (Aprilia, 2012). Karena lingkungan merupakan salah satu faktor yang dapat mempengaruhi pembentukan dan perkembangan perilaku seseorang. Lingkungan selalu ada di sekitar kita dan dapat memberikan dampak positif maupun negatif terhadap perilaku masyarakat yang ada dalam lingkungan tersebut.

14. Susu formula

Kemajuan teknologi berdampak hingga pergeseran nilai sosial budaya di masyarakat hingga memberikan ASI pada anak dianggap tidak modern dan menggambarkan ibu dalam posisi yang rendah. Didukung gencarnya promosi yang dilakukan oleh produsen susu formula hingga membuat susu formula dianggap sebagai pengganti yang lebih baik dibandingkan ASI (Masykur dan Nurafifah, 2014).

15. Psikologis ibu

Pengaruh secara psikologis terhadap pemberian ASI eksklusif berasal dari rasa takut ibu jika kehilangan daya tarik sebagai wanita (Masykur dan Nurafifah, 2014). Anggapan para ibu masa kini tentang menyusui yang dapat merusak penampilan hingga tekanan batin.

\section{KESIMPULAN DAN SARAN}

Pemberian ASI eksklusif pada bayi mulai dari bayi baru lahir hingga setidaknya enam bulan harus dipenuhi dengan lengkap. Karena ASI eksklusif memiliki banyak manfaat diantaranya untuk pembentukan daya tahan tubuh bayi. Selain itu ASI juga membantu mempercepat pengurangan lemak pada tubuh ibu sewaktu hamil. Namun dalam pemberian ASI eksklusif dapat dipengaruhi oleh beberapa hal sehingga mengganggu keberhasilan ASI secara eksklusif. Berdasarkan analisis secara literature review setidaknya didapat 16 faktor antara lain paritas ibu (jumlah kelahiran hidup yang dimiliki seorang ibu), pekerjaan ibu, pengetahuan ibu, sikap ibu, tindakan ibu, dukungan keluarga atau suami, tingkat pendidikan, IMD (Inisiasi Menyusui Dini), usia ibu, dukungan petugas kesehatan, ketersediaan ruang laktasi di tempat kerja, keterpaparan informasi, pendapatan keluarga, lingkungan, susu formula, dan kondisi psikologis ibu.

\section{DAFTAR RUJUKAN}

1] Abdullah, G. I. \& Ayubi, D. (2013) Determinan Perilaku Pemberian Air Susu Ibu Eksklusif pada Ibu Pekerja. Jurnal Kesehatan Masyarakat Nasional. Vol. 7 No. 7.

2] Afifah, D. N. (2007) Faktor yang Berperan dalam Kegagalan Praktik Pemberian ASI Eksklusif. UNDIP. Tesis.

3] Anugerahani, H. S. \& Kartasurya, M . I. (2012) Faktor Risiko Kejadian Stunting pada Anak Usia 12-36 Bulan di Kecamatan Pati, Kabupaten Pati. Journal Of Nutrition College. Vol. 1 No. 1.

4] Aprilia, G. (2012) Hubungan Tingkat Pengetahuan Ibu tentang Asi Eksklusif dengan Pemberian ASI Eksklusif di Desa Harjobinangun Purworejo. Jurnal Komunikasi Kesehatan. Vol. 3 No. 2. 
5] BKKBN. (2006) Deteksi Dini Komplikasi Persalinan. Jakarta: BKKBN.

6] BKKBN. (2012) BPS: Survey Demografi dan Kesehatan Indonesia (SDKI) 2012. Jakarta.

7] Devita, R. (2013) Faktor-Faktor yang Berhubungan dengan Pemberian ASI Eksklusif. Jurnal Kebidanan dan Keperawatan. Vol. 9 No. 1.

8] Dinas Kesehatan Provinsi Jawa Timur. (2016) Profil Kesehatan Provinsi Jawa Timur Tahun 2016. Kementerian Kesehatan RI.

9] Eugenie, T., Batlejeri, J. \& Napitupulu, M. (2015) Pengetahuan Ibu Merupakan Faktor Dominan dalam Pemberian ASI Eksklusif. Jurnal Ilmu dan Teknologi Kesehatan. Vol. 2 No. 2.

10] Hastuti, B. W., Machfudz, S. \& Febriani, T. B. (2015) Hubungan Pengalaman Menyusui dan Tingkat Pendidikan Ibu dengan Pemberian ASI Eksklusif di Kelurahan Barukan, Kecamatan Manisrenggo, Kabupaten KLATEN. JKKI. Vol. 6 No. 4.

11] Masykur, M. \& Nurafifah, D. (2014) Hubungan Dukungan Suami dengan Pemberian ASI Eksklusif di Desa Keben Kecamatan Turi Kabupaten Lamongan. SURYA. Vol. 01 No. XVII.

12] Maulida, H., Afifah, E. \& Sari, D. P. (2015) Tingkat Ekonomi dan Motivasi Ibu dalam Pemberian ASI Eksklusif pada Bayi Usia 06 Bulan di Bidan Praktek Swasta. Jurnal
Ners dan Kebidanan Indonesia. Vol. 3 No. 2.

13] Nasution, S. I., Liputo, N. I. \& Mahdawaty. (2016) Faktor-Faktor yang Berhubungan dengan Pola Pemberian ASI Eksklusif di Wilayah Kerja Puskesmas Bungus Tahun 2014. Jurnal Kesehatan Andalas. Vol. 5 No. 3 .

14] Prasetyono, D., S. (2009) Buku Pintar ASI Eksklusif Pengenalan, Praktik, dan Kemanfaatan-kemanfaatannya. Jogjakarta: DIVA Press.

15] Rahmawati, M. D. (2010) Faktor-Faktor yang Mempengaruhi Pemberian ASI Eksklusif pada Ibu Menyusui di Kelurahan Pedalangan Kecamatan Banyumanik Kota Semarang. Jurnal KesMaDasKa. Vol. 1 No. 1.

16] Sugiarti, E., Zulaekah, S., \& Puspowati, S. D. (2011) Faktor-Faktor yang Berhubungan dengan Pemberian ASI Eksklusif di Kecamatan Karangmalang Kabupaten Sragen. Jurnal Kesehatan. Vol. 4 No. 2.

17] Undang-Undang Republik Indonesia Nomor 36 Tahun 2009 Tentang Kesehatan.

18] WHO. (2014) Global Nutrition Targets 2025 Breastfeeding Policy Brief. Geneva : Department of Nutrition for Health and Development.

19] Widdefrita. \& Mohanis. (2013) Peran Petugas Kesehatan dan Status Pekerjaan Ibu dengan Pemberian ASI Ekslusif. Jurnal Kesehatan Masyarakat Andalas. Vol. 8 No. 1. 